\title{
Effect of high temperature heating on mineralogy, microstructure, shear stiffness and tensile strength of two Australian mudstones
}

Authors: Xianfeng Liu ${ }^{1}$, Chonglei Zhang ${ }^{2}$, Shengyang Yuan ${ }^{3}$, Stephen Fityus ${ }^{4}$, S.W Sloan ${ }^{5}$ and Olivier Buzzi ${ }^{6}$

\section{Affiliations:}

${ }^{1,2,3,4,5,6}$ Priority Research Centre for Geotechnical and Materials Modelling, The University of Newcastle, Callaghan, NSW, 2308, Australia.

${ }^{1,3,4,5,6}$ ARC Centre of Excellence for Geotechnical Sciences and Engineering, the University of Newcastle Australia, Callaghan Campus, EA Building, 2308, Newcastle NSW, Australia.

${ }^{2}$ Key Laboratory of Mountain Hazards and Earth Surface Processes, Institute of Mountain Hazards and Environment, Chinese Academy of Sciences, Chengdu 610041, China.

${ }^{1}$ Research Associate, Email: Xianfeng.liu@,newcastle.edu.au

${ }^{2}$ Assistant Research Scientist, Email: chongleizhang2010@163.com

${ }^{3}$ Ph.D. candidate, Email: Shengyang.yuan@uon.edu.au

${ }^{4}$ Professor, Email: Stephen.fityus@newcastle.edu.au

${ }^{5}$ Laureate Professor, E-mail: scott.sloan@,newcastle.edu.au

${ }^{6}$ Associate Professor, Email: Olivier.buzzi@newcastle.edu.au

Corresponding author: Dr. O.P. Buzzi, Olivier.buzzi@newcastle.edu.au 


\section{Abstract:}

This study falls in the context of underground coal fires (UCF) where burning coal can elevate the temperature of a rock mass in excess of thousand degrees. The objective of the research is to experimentally characterize the change in mechanical behaviour, mineralogy and microstructural texture of two sedimentary rocks when subjected to temperatures up to $1200{ }^{\circ} \mathrm{C}$ for 24 hours. Specimens of local sandstone and mudstone were comprehensively characterized by X-ray diffraction and thermal-gravimetric analysis. These analyses were complemented by optical microscopy and scanning electron microscopy observations on polished thin sections. In addition, pore size distributions of these heated rocks were inferred by means of mercury intrusion porosimetry. These results were extended to an estimation of the intrinsic permeability using the Katz and Thompson model. Investigations at micro scale were followed by mechanical testing (both unconfined and confined compression tests) on cylindrical specimens of heated rocks. Results show that the unconfined compressive strength (UCS) of both rock types tends to increase when the temperatures increases up to $900{ }^{\circ} \mathrm{C}$, beyond which the UCS tends to slightly decrease. As for the permeability, a clear increase in intrinsic permeability was observed for both rocks. The macrospic behaviour was found to be fully consistent with the changes observed at micro scale.

Key words: Underground coal fires, sedimentary rock, mineralogy, microstructure, MIP, SEM 


\section{Introduction}

Underground coal fires are affecting many countries (e.g. India, China, USA, Australia, to name a few) and are extremely problematic. Not only they result in the loss of valuable nonrenewable resources but they are also detrimental to mine safety, infrastructure and threaten the natural environment through their contribution to greenhouse gas emissions $\left(\mathrm{CO}_{2}\right.$ and $\left.\mathrm{CO}\right)$ (Stracher and Taylor 2004; Sinha and Singh 2005; Kuenzer et al. 2007, to name few). Such underground fire has been burning for thousands of year at a site called "Burning Mountain" not far from Newcastle, NSW, Australia (Rattigan 1967). The origin of such fires can be anthropogenic (typically when mining activities are involved) or occur naturally. In particular, one cause of fire is the ability of some coals to self-ignite as the result of an exothermic oxidation reaction (Beamish et al. 2001; Bell et al. 2001; Kaymakci \& Didari 2002).

Underground coal fires are characterized by very elevated temperatures (in excess of $1000^{\circ}$ C) because of the surrounding ground slowing down the heat dissipation and very slow burning kinetics, due to the limited availability of oxygen underground (Stracher and Taylor 2004; Voigt and Rüter 2005). However, it has been showed that the physical phenomena involved in the fire progression are complex and can lead to more oxygen reaching the fire. Indeed, continuous combustion of a coal seam typically leads to a progressive collapse of the overburden soil/rock mass, that is left unsupported, and to the formation of large cracks, which provide new air circulation paths allowing the fire to propagate (Ide et al., 2010). So far, the effect of heat generated by the fire on the hydraulic and mechanical properties of the rock mass has been overlooked. However, this is a critical effect to account for if one wants to model underground coal fire propagation (Liu et al. 2012) and possibly fire extinguishment. This experimental study aims at investigating the influence of high temperature on the 
mechanical behaviour of some local sedimentary rocks, similar to those found in the overburden rock mass of burning mountain (Rattigan 1967).

The impact of high temperature on the physical and mechanical properties of rocks have been largely investigated over the last several decades in different engineering fields such as underground coal gasification or nuclear waste disposal (Dmitriev 1972; Somerton 1992, to name few). These studies found that, in addition to the external stress, two key factors govern the changes in rocks when subjected to high temperatures: mineral thermal expansion and mineral thermal reaction (Tian et al. 2012, 2014). The former may induce great internal thermal stresses as a consequence of the differences in thermalexpansion characteristics of minerals, resulting in thermal cracking and strength degradation (David et al. 1999; Keshavarz et al. 2010). On the other hand, mineral thermal reaction may result in some new bonding agents, which can strengthen the rocks (Luo and Wang 2011). The predominance of one phenomenon over the other depends on the mineral composition of rocks, thermal loading conditions (temperature and its change rate, heating and cooling cycle) and external stress state (see e.g. Zhang et al. 2009; Ranjith et al. 2012; Brotóns et al. 2013).

So far, most studies focused on the thermal effects on rocks when exposed to high temperature at macro scale with only a few studies attempting to investigate their fundamental physico-chemical mechanisms from a microscopic perspective (e.g. Hajpál and Török 2004; Wolf 2006; Keshavarz et al. 2010; Yavuz et al. 2010).

The present experimental work aims at investigating the changes at both micro and macro scales of two Australian sedimentary rocks (sandstone and mudstone) after being subjected to heating treatment at high temperatures (up to $1200{ }^{\circ} \mathrm{C}$ ). The paper presents the results of a range of tests, including X-ray diffraction, thermal-gravimetric analysis, optical microscopy, back-scattered scanning electron microscopy, pore size distribution, unconfined compression 
tests and triaxial tests. The evolution of the rocks intrinsic permeability with heating treatment is also discussed. The objective is to provide quality data to allow the modelling of underground coal fire propagation involving possible failure of the overburden rock mass and the formation of cracks. This actual modelling exercise is beyond the scope of this paper.

\section{Materials}

Two sedimentary rocks were collected from a mining site in Hunter Valley, New South Wales, Australia. Note that those samples were from the same site as for the samples presented in Liu et al. (2015). However, further investigation shows that there are significant differences in their minerology between the samples from two collections. Figure 1 shows disc specimens of two rocks and their images obtained from transmitted light microscopy observation. These images show that about $79.4 \%$ (Fig.1c) and $94.4 \%$ (Fig.1d) of matrix is made of particles smaller than $30 \mu \mathrm{m}$, which confirms that both rocks are mudstone (referred to as M1 and M2, respectively) (Berkman 2001). The M1 contains clear horizontal bedding planes (Fig.1a) while the M2 seems homogenous (Fig.1b). The optical microscopy analysis also shows similar dominant mineral components (e.g. quartz, clay minerals, muscovite, feldspar, siderite) in both mudstones, whereas dolomite can only be identified in the M2 (Fig.1d) but not in the M1 (Fig.1c). In addition, the specific gravity of powdered mudstones was measured using an automatic gas pycnometer (Micromeritics Autopyc II 1340, accuracy of $0.05 \%$ ) and the bulk density of intact rocks dried in an oven at $100{ }^{\circ} \mathrm{C}$ were also determined following ASTM standard (ASTM-D4404-10 2010).

The main physical properties of these mudstones and their main mineralogical composition are summarized in Table 1. 
Table 1. Physical properties and dominant mineral composition of mudstones tested

\begin{tabular}{clccc}
\hline $\begin{array}{c}\text { Rock } \\
\text { type }\end{array}$ & $\begin{array}{c}\text { Mineralogical composition from } \\
\text { optical microscopy observation } \\
\text { on thin sections }\end{array}$ & $\begin{array}{c}\text { Specific } \\
\text { gravity } \\
\left(\mathrm{G}_{\mathrm{s}}\right)\end{array}$ & $\begin{array}{c}\text { Bulk } \\
\text { density } \\
\left(\mathrm{g} / \mathrm{cm}^{3}\right)\end{array}$ & $\begin{array}{c}\text { Initial } \\
\text { porosity } \\
(n)\end{array}$ \\
\hline $\begin{array}{c}\text { Mudstone } \\
(\mathrm{M} 1)\end{array}$ & $\begin{array}{c}\text { Clay minerals, Quartz, Siderite, } \\
\text { Muscovite, Feldspar }\end{array}$ & 2.71 & 2.40 & 0.11 \\
\hline $\begin{array}{c}\text { Mudstone } \\
(\mathrm{M} 2)\end{array}$ & $\begin{array}{l}\text { Clay minerals, Quartz, Siderite, } \\
\text { Muscovite, Feldspar, Dolomite }\end{array}$ & 2.68 & 2.38 & 0.11 \\
\hline
\end{tabular}

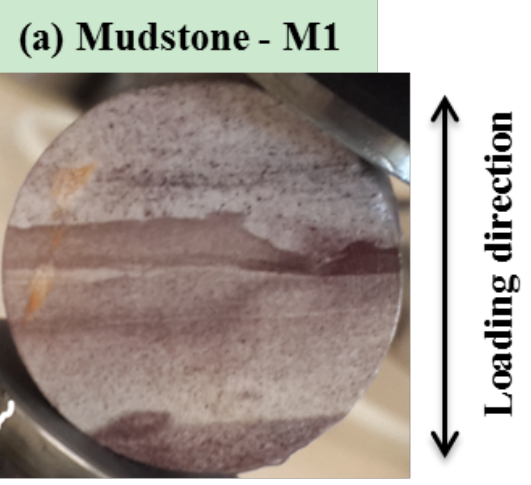

(c) M1-Thin section image

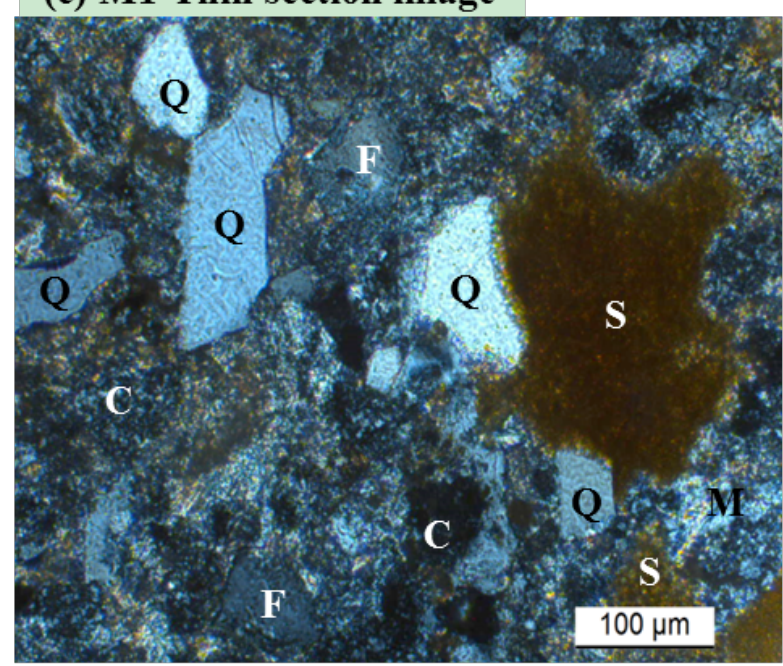

Q- Quartz M- Muscovite F- Feldspar

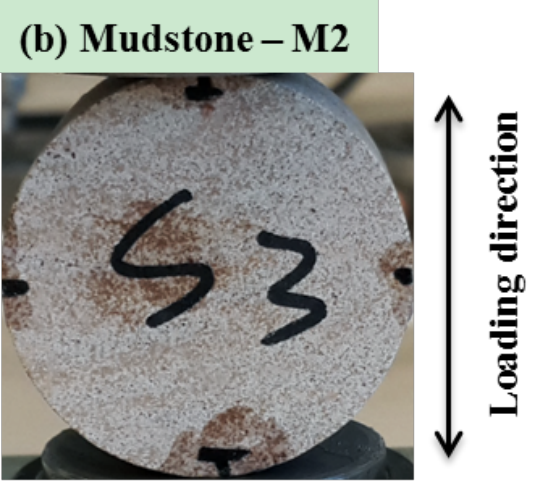

(d) M2-Thin section image

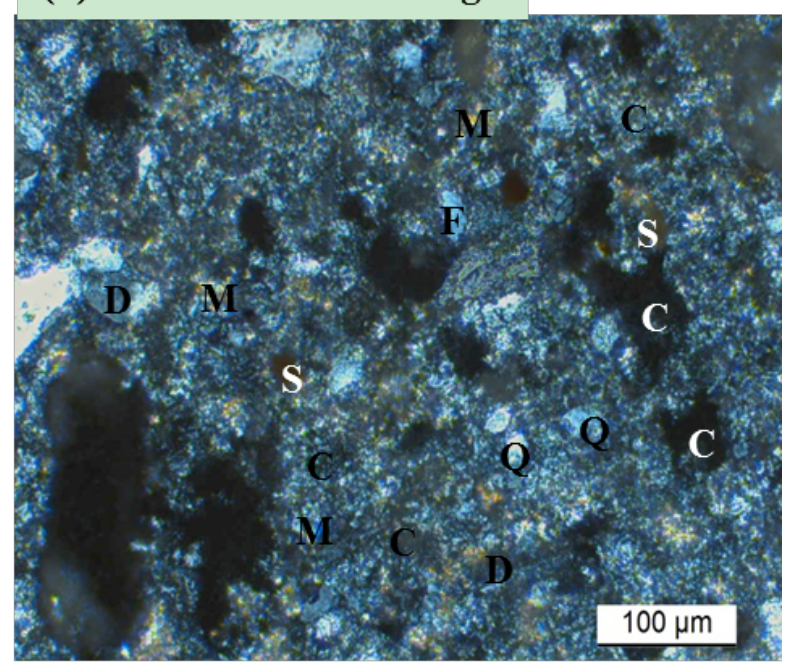

S- Siderite D-Dolomite C-Clay minerals

Fig.1. View of the two specimens of mudstones tested and transmitted light microscopy images on thin sections: M1 (a, c) and M2 (b, d). 


\section{Experimental program and methods}

\subsection{Experimental program}

This experimental study aims at characterizing the changes in both macro and micro properties of two Australian mudstones when exposed to temperature up to $900^{\circ} \mathrm{C}$. To do so, following the heating treatment at different temperatures (Table 2), bender element tests are carried out on the heated disc specimens prior to being subject to splitting tests (Brazilian test). The macro testing is complemented by further investigation at micro scale. Such micro investigations include mineralogy determination by a combination of semi-quantitative X-ray diffraction analysis (XRD) and thermal-gravimetric analysis (TGA) as well as optical microscopy observation on thin sections $(\mathrm{OM})$, pore size distribution by mercury intrusion porosimetry (MIP) and analysis of microstructural texture by back-scattering scanning electron microscopy observation (SEM combined with energy dispersive spectroscopy (EDS).

Table 2 summarizes all the macro and micro scale testing conducted. The methodology of each type of experiment is detailed in the upcoming sections.

Table 2 Experimental program for multi-scale testing. SWV: Shear wave velocity measurement, ST: Splitting test or Brazilian test, TGA: Thermal-gravimetric analysis, XRD: semi-quantitative X-ray diffraction analysis, OM: Optical microscopy observation (both transmitted and reflected lights) on polished thin section, MIP: mercury intrusion porosimetry, BS-SEM: Back-scattering Scanning Electron Microscopy observation. Note that all number 2 stands for one test for each rock while number 4 stands for two tests for each rock.

\begin{tabular}{cccccccc}
\hline Heating temperature $\left({ }^{\circ} \mathrm{C}\right)$ & SWV & ST & TGA & XRD & OM & MIP & BS-SEM \\
\hline 100 & 4 & 4 & 2 & 2 & 2 & 2 & 2 \\
\hline 300 & 4 & 4 & - & 2 & - & 2 & - \\
\hline 450 & 4 & 4 & - & 2 & - & 2 & - \\
\hline 600 & 4 & 4 & - & 2 & 2 & 2 & 2 \\
\hline 750 & 4 & 4 & - & 2 & - & 2 & - \\
\hline 900 & 4 & 4 & - & 2 & 2 & 2 & 2 \\
\hline
\end{tabular}




\subsection{Experimental Methods}

\subsubsection{Specimen preparation and heating treatment}

All rock specimens were cored in blocks retrieved from the mine site. In order to keep the samples as much as comparable in terms of their mineralogy and natural structure, only one big block of each type of mudstone was used for this purpose. The cored cylindrical specimens were further cut into circular disc specimens having dimensions of $35.4 \mathrm{~mm}$ in diameter and $20.2 \mathrm{~mm}$ in thickness by following ASTM-D4543-08 and ASTM-D3967-08. Note that the specimens for M1 were prepared while keeping the bedding plan along diametric direction as indicated in Fig. 1a.

After being subject to drying in a $100^{\circ} \mathrm{C}$ oven for 24 hours, the disc specimens were then placed in a temperature-controlled furnace to expose the material to five target temperatures as shown in Table $2\left(300,450,600,750,900{ }^{\circ} \mathrm{C}\right)$. The target temperature was reached at a rate of $1{ }^{\circ} \mathrm{C} /$ hour and was maintained for 24 hours. The cooling rate occurred at $25{ }^{\circ} \mathrm{C} /$ hour. Both starting and finishing temperatures were $20^{\circ} \mathrm{C}$.

\subsubsection{Shear wave velocity measurement}

Shear wave velocity measurements were conducted on the specimens along the diametric direction. Note that the wave propagation direction is normal to bedding plan for M1 (Fig.1a). Fig.2 presents the schematic testing set-up for shear wave velocity measurement. Two ultrasonic transducers (Panametrics-NDT/V152/10 MHz) were respectively fixed on two parallel steel plates connected by two linear guides to ensure their good alignment. Input signals were generated and emitted using a programmable function generator ( $\left.\mathrm{TT}^{\circledR}{ }^{\circledR} / 40 \mathrm{MHz} / \mathrm{DDS}\right)$. These signals were further amplified by using a high voltage amplifier (Pintek ${ }^{\circledR}$ HA-400). Output signals were also amplified by using an ultrasonic pre-amplifier 
OLYMPUS $^{\circledR}$ (Panametrics 5656C with a gain of 40dB). Both input and output signals were acquired through a digital oscilloscope (Tektronix ${ }^{\circledR}$, TDS, 1001C-EDU). To determine travel time of shear wave, the arrival time approach (first break pick-up) was adopted as detailed in Arroyo et al. 2010.

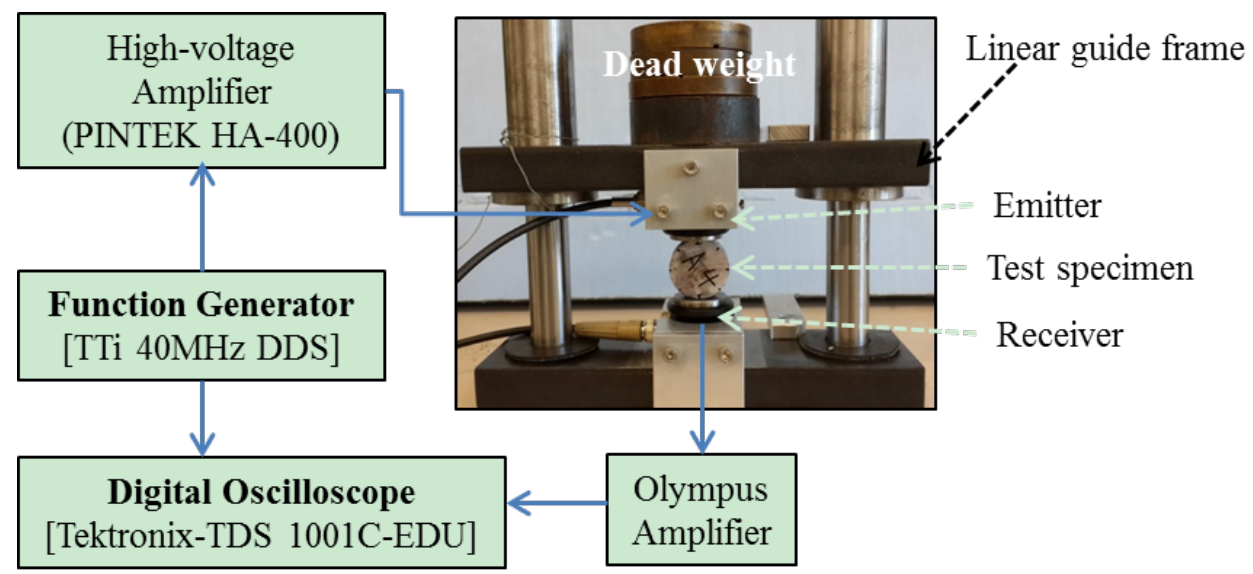

Fig.2 Experimental set-up for measuring shear wave velocity of mudstones tested

The measured shear wave velocity values $\left(v_{\mathrm{s}}\right)$ were used to derive the low-strain shear modulus $\left(\mathrm{G}_{0}\right)$ of heated mudstones as $G_{0}=\rho_{b} \cdot v_{s}^{2}$, where $\rho_{b}$ is the bulk density of specimen (ASTM-D2845-08).

\subsubsection{Splitting test (Brazilian test)}

Following the ASTM standard D3967-08, splitting tests were performed on the heated mudstone specimens having a thickness-to-diameter ratio of $0.57(35.4 \mathrm{~mm}$ in diameter and $20.2 \mathrm{~mm}$ in thickness). The loading directions as indicated in Fig. 1a and 1b were the same those along which the shear wave velocity measurements were conducted. Fig.3 presents the experimental set-up for splitting tests. The steel frame with linear guides was again used to ensure the parallelization of the loading plates. In addition, two pieces of $3 \mathrm{~mm}$ thick cardboard cushion were placed between the bearing plates and the specimen (Fig. 3b) to reduce possible high stress concentration (as recommended by ASTM standard D3967-08). 
Finally, a Geocom ${ }^{\circledR}$ compression system with a capacity of $70 \mathrm{kN}$ was employed for loading and a loading rate of $0.45 \mathrm{~mm} / \mathrm{min}$ was applied.
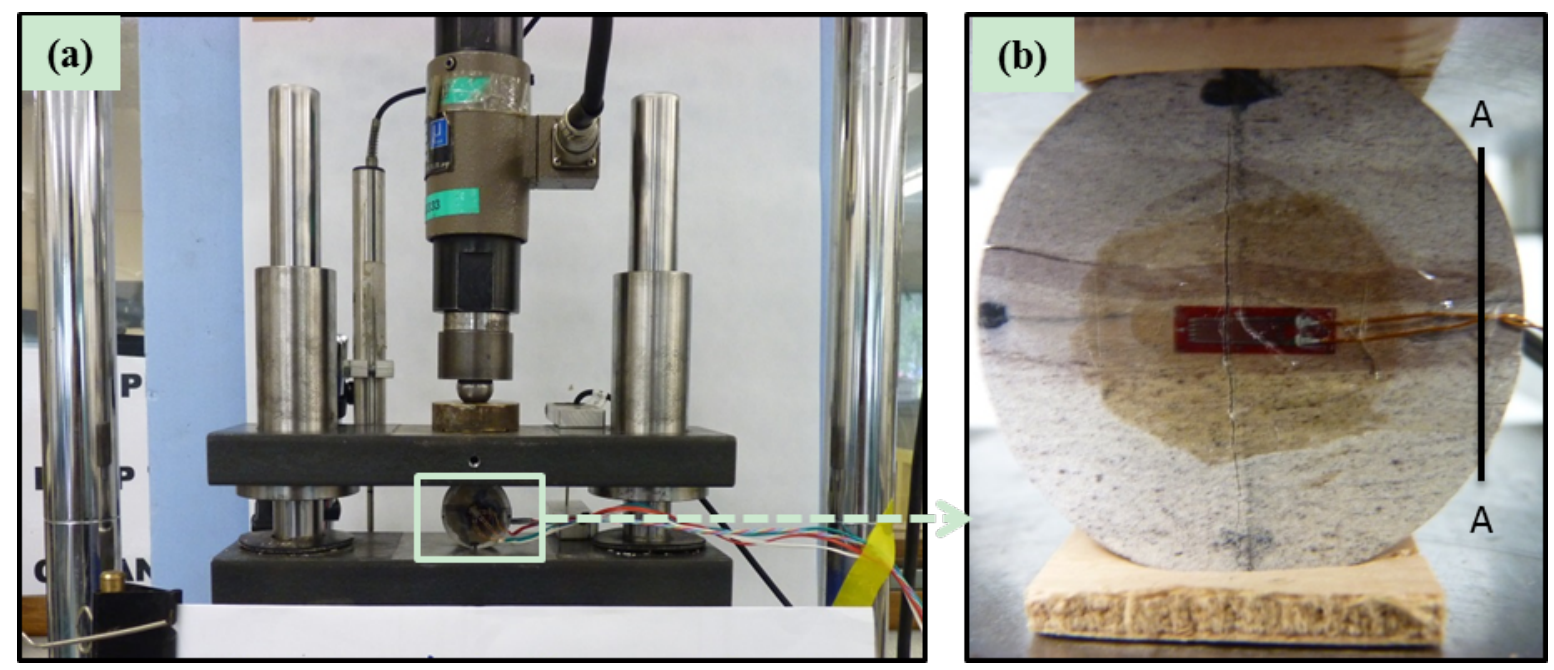

Fig.3. Experimental set-up for splitting test (a) and a typical failed specimen between two 3 mm thick cardboard cushions ( $\mathrm{M} 1$ heated at $\left.600^{\circ} \mathrm{C}\right)(\mathrm{b})$

\subsubsection{Thermal-gravimetric analysis (TGA)}

Following the splitting tests, powdered rock samples (particle size below $75 \mu \mathrm{m}$ ) were prepared by crushing one failed specimen for each mudstone heated at $100{ }^{\circ} \mathrm{C}$ using mechanical grinder. Thermal-gravimetric analyses were performed on these powdered samples to show the mineralogy changes of mudstones tested in response to heating. The testing procedure and data interpretation described in Pansu and Gautheyrou (2006) was followed. The tests were run under $\mathrm{N}_{2}$ environment whilst raising the temperature of $20{ }^{\circ} \mathrm{C}$ to $1100{ }^{\circ} \mathrm{C}$ at a rate of $5{ }^{\circ} \mathrm{C} / \mathrm{min}$. The mass loss and heat flow were recorded during the heating process, which allows us to determine the critical temperatures at which the thermal reactions of dominant minerals take place and also to quantify the dominant clay minerals. 


\subsubsection{Semi-quantitative X-ray diffraction analysis (XRD)}

Following the same procedure for preparing the powdered samples for TGA, the samples were also prepared from the failed mudstones exposed to different heating temperatures (Table 2). X-ray diffraction analysis was conducted on these samples using a Philips X'Pert multi-purpose diffractometer $\mathrm{XRD}$ with $\mathrm{Cu}$ K-alpha radiation (awavelength of $1.5406 \AA$ ), following the procedure described in Moore and Reynolds (1989). The diffraction pattern was recorded in $2 \theta$ steps of $0.007^{\circ}$ during a continuous scan with a range of $2 \theta$ varying from $5.0^{\circ}$ to $70^{\circ}$. Finally, the semi-quantitative analysis was performed on the XRD data by using a commercial package SIROQUANT based on ICDD-PDF2 database.

\subsubsection{Optical microscopy (OM) and scanning electron microscopy (SEM) observations}

In order to visualize the changes in dominant minerals and related texture of mudstones tested in response to heating, both transmission and reflection light microscopy observations were performed on polished thin sections. These thin sections were prepared from the rock parts retrieved from the mudstones previously heated at 100, 600 and $900{ }^{\circ} \mathrm{C}$, which were subjected to the splitting test. To minimize the mechanically-induced microcracks, only the rock parts from the perimeter of specimen as indicated by A-A line in Fig.3b were used for the purpose. These thin sections were further analyzed by using back-scattering SEM. The energy dispersive spectroscopy (EDS) technique was also employed for the chemical analysis on different spots of interest on the surface of thin sections. To do so, a field emissionmicroscope Zeiss Sigma VP FESEM was used and all the specimens were subjected to carbon coating prior to SEM observations. 


\subsubsection{Mercury intrusion porosimetry (MIP)}

To emphasize the thermally-induced changes in pore size distribution of mudstones tested, the MIP tests were conducted on heated rock specimens after splitting tests using a Micromeritics AutoPore (IV 9500). These specimens were some off-cuts collected from the perimeter of failed circular disc specimen as indicated by the right side of A-A line in Fig. $3 \mathrm{~b}$, which were again dried in a $100{ }^{\circ} \mathrm{C}$ oven prior to MIP testing. During the MIP testing, the mercury pressure was incrementally raised to the maximum value of the apparatus (228 $\mathrm{MPa})$, which corresponds to an equivalent entrance pore diameter of $0.0065 \mu \mathrm{m}$. The interpretation of MIP data is based on the Washburn equation (Washburn, 1921), which relates the applied mercury injection pressure $p$ to an equivalent entrance pore size $d$, as described by Equation 1:

$$
p=\frac{-4 \sigma_{H g} \cos \theta_{n w}}{d}
$$

where $\sigma_{H g}$ is the surface tension of mercury $\left(0.484 \mathrm{~N} / \mathrm{m}\right.$ at $25^{\circ} \mathrm{C}$, as adopted by Diamond, 1970) and $\theta_{n w}$ is the mercury-mineral contact angle (assumed equal to $140^{\circ}$ as adopted by Romero, 1999). Values of the void ratio associated with intruded mercury are computed from the test results obtained during the intrusion stage as $\mathrm{e}_{\mathrm{MIP}}=\mathrm{V}_{\text {mercury }} / \mathrm{V}_{\text {solids }}$, where $\mathrm{V}_{\text {solids }}$ is the volume of the specimen used for the MIP test and $\mathrm{V}_{\text {mercury }}$ is the cumulative volume of intruded mercury at the current pressure. The pore size density (PSD) function is estimated from the derivative of the cumulative intrusion curve. The more details regarding MIP testing can be referred to Liu et al. 2015a,b. 


\section{Results and discussion}

\subsection{Changes at macro scale}

\subsubsection{Changes in physical parameters of heated rocks}

Fig. 4 presents changes in mass loss ratio, volumetric deformation and porosity as well as specific gravity of the disc rock specimens subjected to heating treatment. Note that the positive sign of volumetric deformation stands for the specimen expansion while the negative sign represents the specimen shrinkage. We can observe clear changing trends: the higher the temperature, the more the mass loss and the specimen expansion as well as the higher the void ratio. Interestingly, the small shrinkage (less than $0.5 \%$ ) can be observed for the specimens heated at $300{ }^{\circ} \mathrm{C}$ and followed by more significant expansion up to $2.5 \%$ for high heating temperatures. This is consistent with the observations by Somerton 1992, showing the general increase in rock volume due to thermal expansion at high temperatures and is characterized by irreversible elongation after cooling down. The combined effects of the mass loss and volume change results in the changes in rock porosity. There seems to be a threshold at about $450{ }^{\circ} \mathrm{C}$ for $\mathrm{M} 1$ and about $600{ }^{\circ} \mathrm{C}$ for $\mathrm{M} 2$, beyond which little change in their porosity takes place. Finally, a slight drop can be seen for the specific gravity of both mudstones in response to heating treatment. 


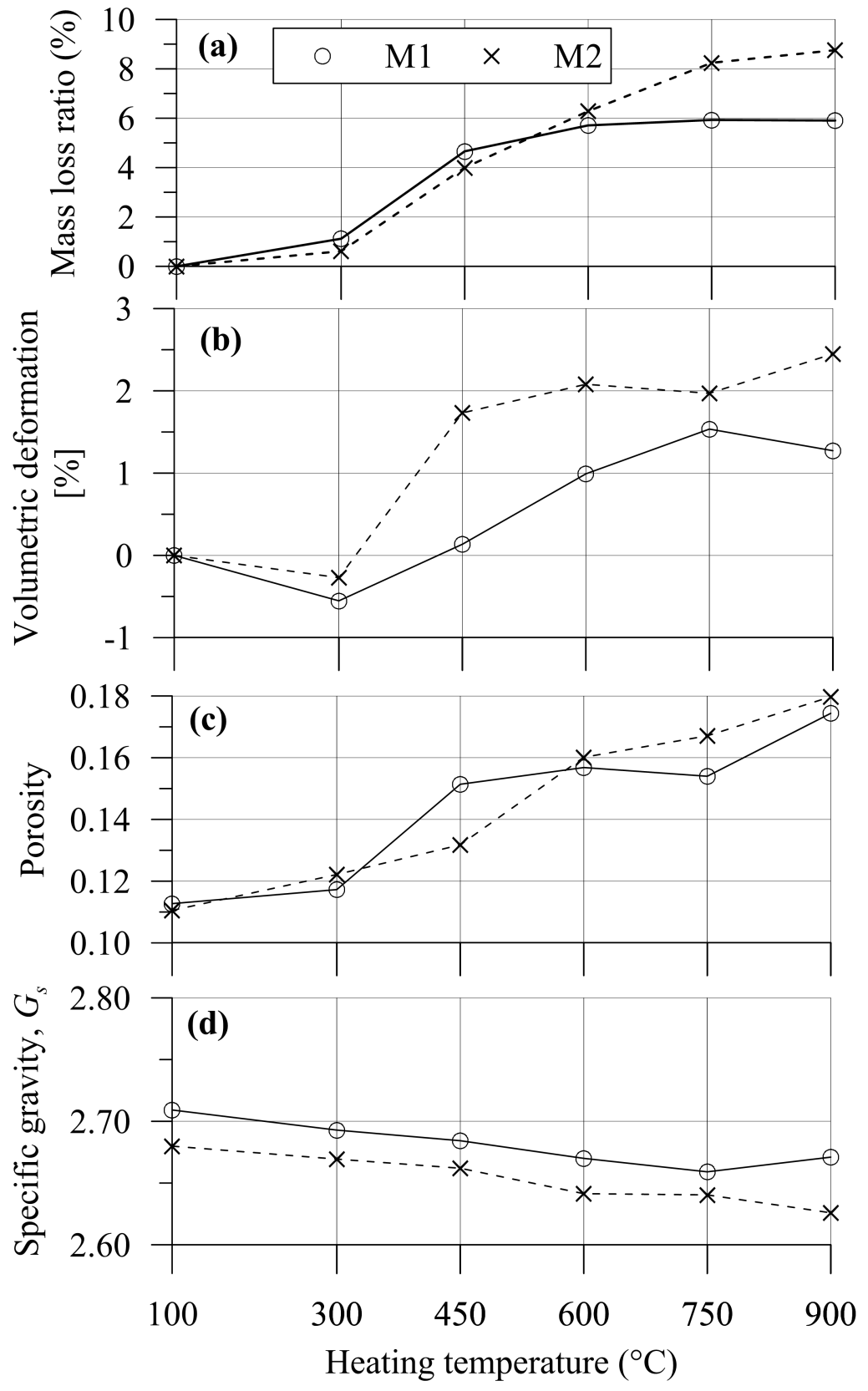

Fig.4. Changes in mass loss ratio (a), volumetric deformation (b), porosity (c) and specific gravity (d) of mudstones when exposed to heating treatment. 


\subsubsection{Changes in shear wave velocity and derived shear stiffness}

Fig.5 shows shear wave velocity measurements $\left(v_{\mathrm{s}}\right)$ of heated mudstones and their corresponding low-strain shear stiffness $\left(\mathrm{G}_{0}\right)$ values. Non-monotonic evolution in both shear wave velocity (Fig.5a) and shear stiffness (Fig.5b) can be observed. For both parameters $\left(v_{\mathrm{s}}\right.$ and $\mathrm{G}_{0}$ ), a considerable increase for the heating temperatures up to $450{ }^{\circ} \mathrm{C}$ is followed by a progressive decrease. In addition, these parameters obtained on heated M2 are significantly higher than those from heated M1. The different response for two mudstones is related to their different mineral compositions (Fig.1) and the thermal reactions of those dominant minerals. This will be evidenced in the upcoming sections on the changes at micro scale.

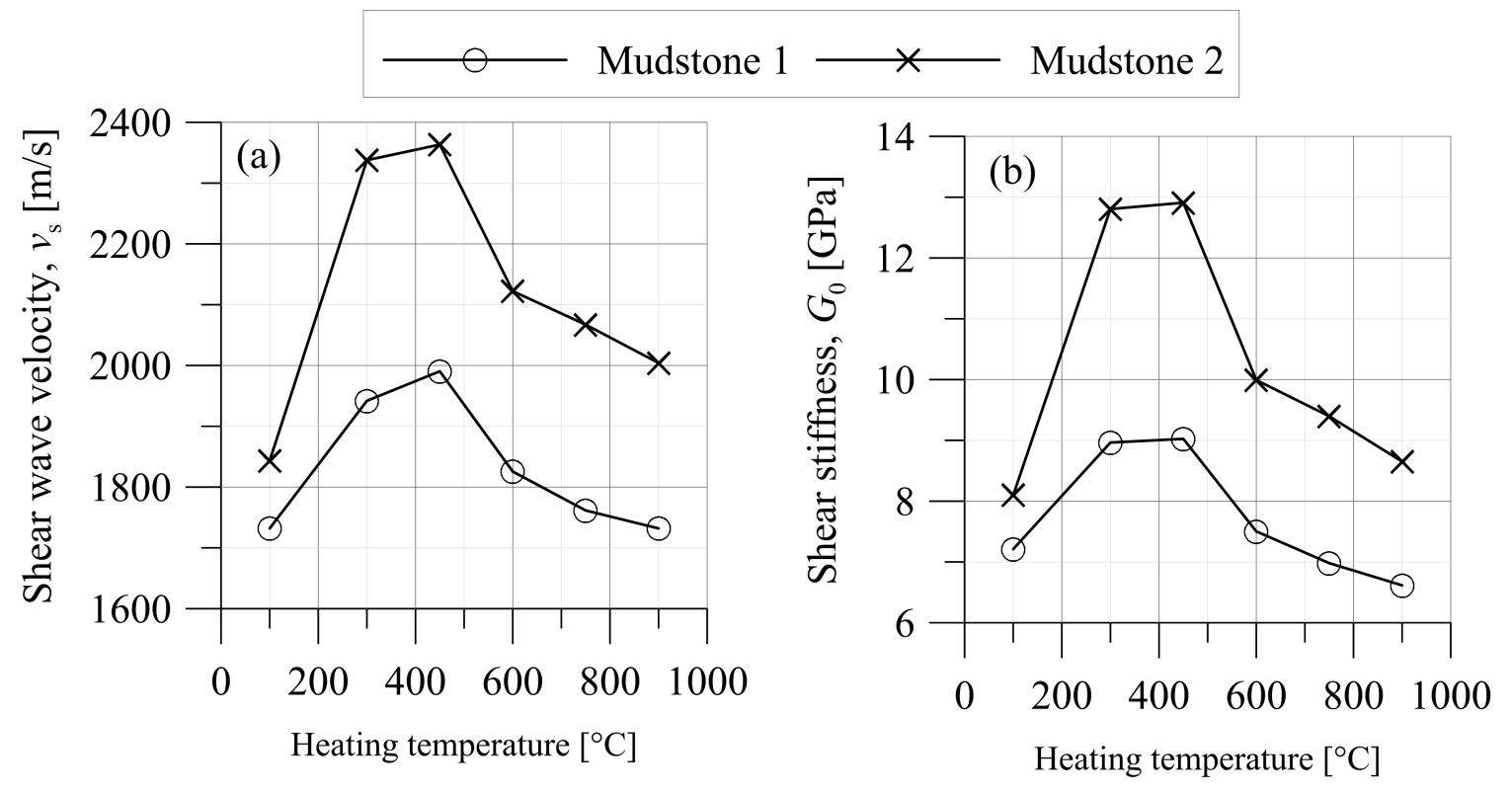

Fig.5. Changes in shear wave velocity (a) and derived shear stiffness (b) of heated mudstones. Note that each data point is an average values obtained from duplicate specimens.

\subsubsection{Changes in tensile strength}

Fig. 6 presents changes in splitting tensile strength of mudstones when exposed to high temperatures. Consistent with the changes in the shear wave velocity and shear stiffness, the 
splitting tensile strength evolves as well non-monotonically. An initial increase for the heating temperatures up to $450{ }^{\circ} \mathrm{C}$ is followed by a gradual reduction. This changing behavior is more pronounced for M2 while a relative small variation appears for M1. Again, these results will be further understood based on microstructural investigations discussed below.

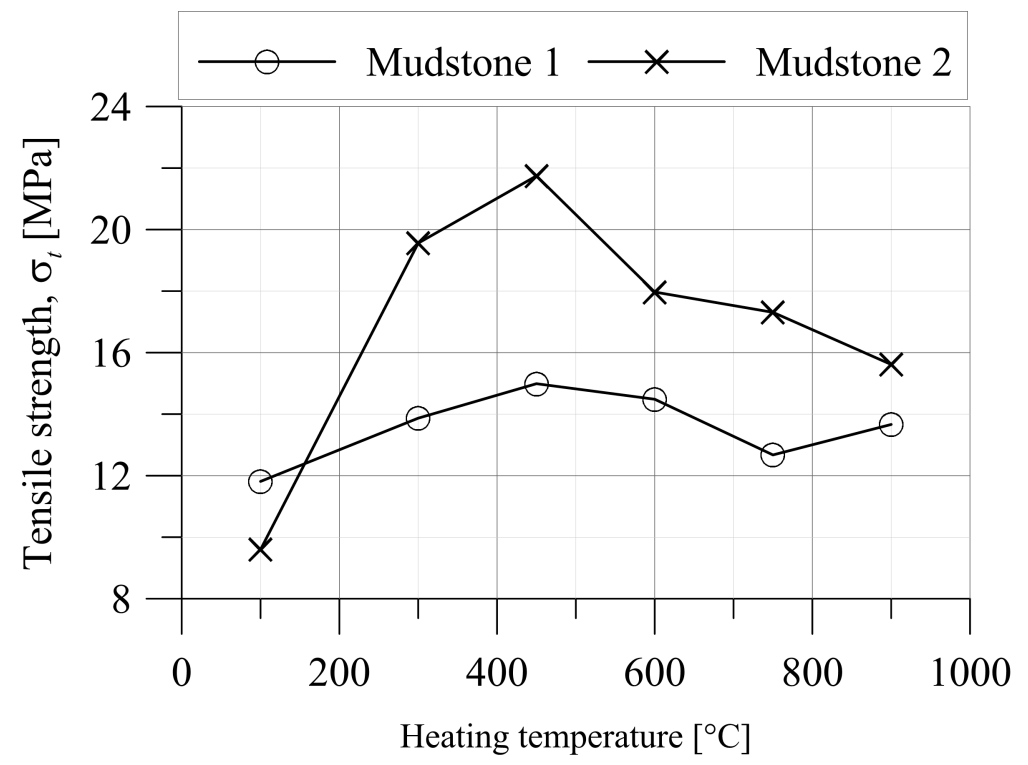

Fig.6. Changes in splitting tensile strength of heated mudstones. Note that each data point is an average values obtained from duplicate specimens.

\subsection{Changes at micro scale}

\subsubsection{Changes in mineralogy of heated rocks}

Figure 7 shows the thermal-gravimetric analysis (TGA) data obtained on the intact rock (only dried at $100^{\circ} \mathrm{C}$ ). Note that the $\mathrm{N}_{2}$ environment under which TGA was conducted is different from the air environment during heating treatment imposed to the rock specimens. The TGA on both mudstones shows a small mass loss and associated differential thermo-gravimetric (DTG) peak below $100^{\circ} \mathrm{C}$. This response is due to the loss of free water, which is possibly untaken by rock powders during storage prior to the TAG analysis. Beyond $100{ }^{\circ} \mathrm{C}$, the dominant mass loss shows a two stage process for M1 while a single stage one for M2, which 
leads to two TG peaks at $516{ }^{\circ} \mathrm{C}$ and $689{ }^{\circ} \mathrm{C}$ for $\mathrm{M} 1$ and one $\mathrm{TG}$ peak at $500{ }^{\circ} \mathrm{C}$ for $\mathrm{M} 2$. These mass losses can be directly related to the loss of structural water, so-called dehydroxylation reaction described by Pansu and Gautheyrou 2006, of clay minerals and muscovite as well as carbonates presenting in both mudstones (Fig. 1) (Dmitriev 1972; Somerton 1992). Further interpretation of the TAG data following Pansu and Gautheyrou 2006 shows that the dominant clay minerals contained in M1 is likely montmorillonite while those in M2 may be kaolinite. These results will be further confirmed by XRD analysis presented below.
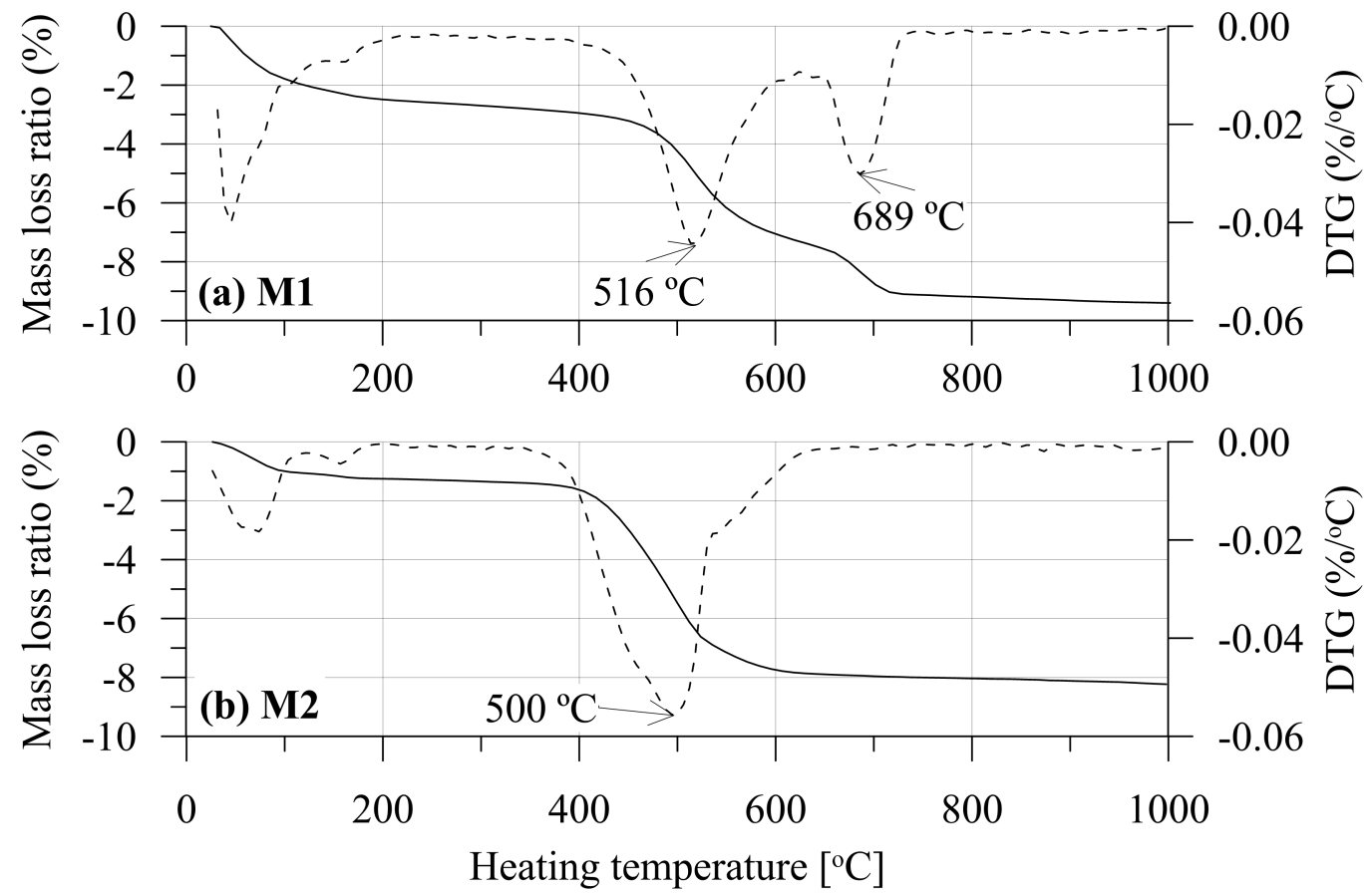

Fig.7. Thermal-gravimetric analysis data in terms of mass loss ratio and differential thermogravimetry (DTG) for M1 (a) and M2 (b).

Following the TGA on intact mudstones, the XRD analyses were conducted on heated specimens (Table 2) in order to track the changes in mineralogy occurring as a result of the heat treatment (see Figure 8). Note that in order to enhance the clarity of XRD pattern, only 
the spectra data over a range of $2 \theta$ below $40^{\circ}$ are presented since these data include all the dominant peaks. The semi-quantitative mineralogical analysis is summarized in Table 3.

We can observe that the dominant peaks of the XRD pattern for both rocks are quite similar. The common minerals identified in both intact mudstones (M1 and M2) are quartz, muscovite, feldspar, kaolinite, mixed illite/montmorillonite and siderite ( $\mathrm{Ca}$ and $\mathrm{Mg})$, whereas the $\mathrm{Fe}$ bearing dolomite and Zirconium dioxide can be only identified in M2 (Fig. 1 and Fig.8). Further semi-quantitative analysis (Table 3) shows that apart from the dominant mineral of quartz, the sub-dominant mineral in M1 is mixed Illite/Montmorillonite while that in M2 is kaolinite. This result confirms that obtained from TAG as discussed above.

Upon heating treatment at temperatures up to $900{ }^{\circ} \mathrm{C}$, no significant changes in the diffraction peaks can be observed for quartz and feldspar. This is essentially due to the absence of significant thermal reaction involving these minerals below $900^{\circ} \mathrm{C}$ (Somerton 1992 , Pansu and Gautheyrou 2006). Although the diffraction peaks for muscovite are clearly visible over the whole range of heating temperatures, the muscovite is transformed to its dehydraxylated form when exposed to temperatures over $600{ }^{\circ} \mathrm{C}$. This response is directly a consequence of the so-called dehydraxylation reaction, which likely takes place over a range of heating temperature from 450 to $650{ }^{\circ} \mathrm{C}$ (Somerton 1992).

The interpretation of XRD data clearly shows that some minerals tend to disappear during the heating treatment. This is the case of kaolinite for both $\mathrm{M} 1$ and $\mathrm{M} 2$ (unidentifiable at $600^{\circ} \mathrm{C}$, Fig. 8 and Table 3) and the mixed illite/montmorillonite (disappearing at $900^{\circ} \mathrm{C}$, Fig. 8 and Table 3). The siderite ( $\mathrm{Ca}$ and $\mathrm{Mg}$, syn) also disappears at $600^{\circ} \mathrm{C}$ for both rocks while the $\mathrm{Fe}-$ dolomite can be only identified at temperatures below $750^{\circ} \mathrm{C}$ (Fig. 8 and Table 3). All these observations are quite consistent with the response of TGA. 
Finally, some minerals form as a result of the heat treatment. For instance, Fe-bearing oxides ( $\mathrm{Ca}$ and $\mathrm{Mg}$, syn) can be clearly identified in both mudstones heated at $600{ }^{\circ} \mathrm{C}$ as shown in Fig. 8 and Table 3. This is further confirmed by transmitted and reflected light microscopy observations on polished thin sections (Fig. 9a, 9b, 10a and 10b). Some hematite appears in both mudstones heated at $900{ }^{\circ} \mathrm{C}$ (Fig.8 and Table 3). Again, this can be clearly confirmed by the polarized light microscopy images (Fig.9c, 9d, 10c and 10d). The subsequent appearance of Fe-bearing oxides and hematite can be attributed to the decomposition of Fe-bearing carbonates such as siderite for M1 and both siderite and Fe-dolomite for M2 (Hajpál and Török 1998, 2004). The significance of these newly formed cementation minerals will be highlighted in order to explain the macroscopic changes in splitting tensile strength and shear stiffness. 
(a) M1

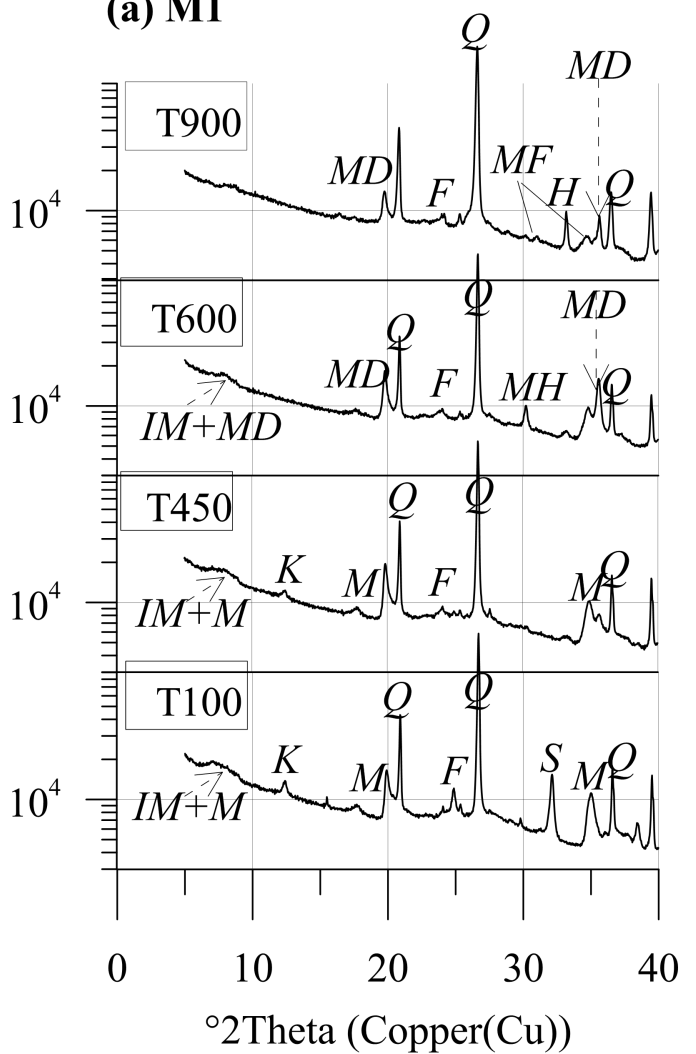

(b) M2

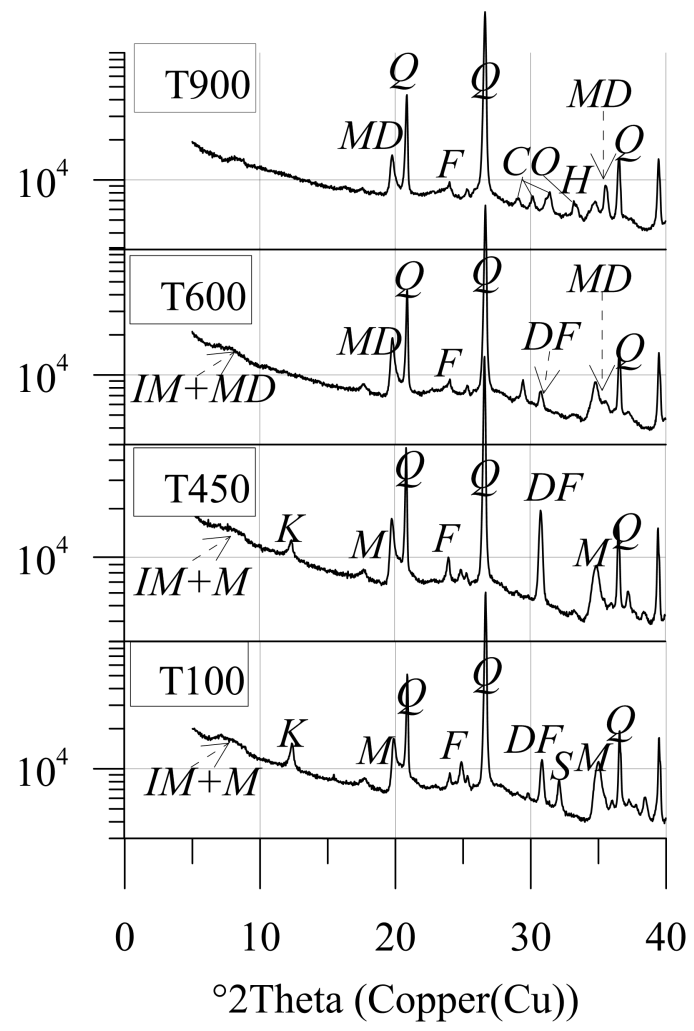

Q: Quartz, M: Muscovite, K: Kaolinite, IM: Mixed Illite/Montmorillonite, DF: Fe-Dolomite, F: Feldspar, S: Siderite (Mg and Ca, syn), H: Hematite, MH: maghemite, MD: Dehydroxylated muscovite, CO: (Ca-Fe-Mg) oxide, MF:Magnesioferrite

Fig.8. XRD results on mudstones subjected to heating treatment at $100,450,600$ and $900{ }^{\circ} \mathrm{C}$ : M1 (a) and M2 (b) 
Table 3. Semi-quantitative XRD analysis on sandstone and mudstone

\begin{tabular}{|c|c|c|c|c|c|c|c|}
\hline \multirow[t]{2}{*}{$\begin{array}{l}\text { Rock } \\
\text { Type }\end{array}$} & \multirow[t]{2}{*}{ Minerals } & & axim & treat & ent, & for he & \\
\hline & & 100 & 300 & 450 & 600 & 750 & 900 \\
\hline \multirow{11}{*}{ 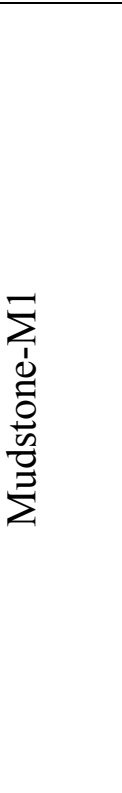 } & Quartz & $\mathrm{D}$ & $\mathrm{D}$ & $\mathrm{D}$ & $\mathrm{D}$ & $\mathrm{D}$ & $\mathrm{D}$ \\
\hline & Mixed Illite/Montmorillonite & SD & SD & SD & SD & A & - \\
\hline & Muscovite & A & $\mathrm{A}$ & A & - & - & - \\
\hline & Kaolinite & $\mathrm{A}$ & $\mathrm{A}$ & $\mathrm{A}$ & - & - & - \\
\hline & Siderite (Mg and $\mathrm{Ca}$, syn) & $\mathrm{A}$ & $\mathrm{A}$ & - & - & - & - \\
\hline & Feldspar & $\operatorname{Tr}$ & $\operatorname{Tr}$ & $\operatorname{Tr}$ & $\operatorname{Tr}$ & $\operatorname{Tr}$ & $\operatorname{Tr}$ \\
\hline & Dehydroxylated muscovite & - & - & - & A & A & A \\
\hline & Fe-bearing oxides (Mg and $\mathrm{Ca}$ ) & - & - & $\mathrm{A}$ & $\mathrm{A}$ & $\mathrm{A}$ & - \\
\hline & Hematite & - & - & - & - & $\operatorname{Tr}$ & $\mathrm{A}$ \\
\hline & Meghemite & - & - & - & $\operatorname{Tr}$ & - & - \\
\hline & Megnesioferrite & - & - & - & - & $\operatorname{Tr}$ & $\mathrm{A}$ \\
\hline \multirow{11}{*}{ 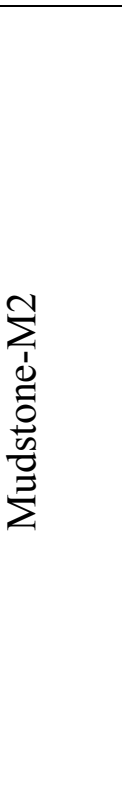 } & Quartz & $\mathrm{D}$ & $\mathrm{D}$ & $\mathrm{D}$ & $\mathrm{D}$ & $\mathrm{D}$ & $\mathrm{D}$ \\
\hline & Kaolinite & SD & $\mathrm{SD}$ & SD & - & - & - \\
\hline & Siderite (Mg and $\mathrm{Ca}$, syn) & $\mathrm{A}$ & $\mathrm{A}$ & - & - & - & - \\
\hline & Fe-Dolomite & A & $\mathrm{A}$ & $\mathrm{A}$ & $\mathrm{A}$ & $\mathrm{A}$ & - \\
\hline & Mixed Illite/Montmorillonite & A & $\mathrm{A}$ & $\mathrm{A}$ & $\mathrm{A}$ & $\mathrm{Tr}$ & - \\
\hline & Muscovite & A & A & A & - & - & - \\
\hline & Feldspar & $\operatorname{Tr}$ & $\operatorname{Tr}$ & $\operatorname{Tr}$ & $\operatorname{Tr}$ & $\operatorname{Tr}$ & $\operatorname{Tr}$ \\
\hline & Zirconium dioxide & $\operatorname{Tr}$ & $\operatorname{Tr}$ & $\operatorname{Tr}$ & $\operatorname{Tr}$ & $\operatorname{Tr}$ & $\operatorname{Tr}$ \\
\hline & Dehydroxylated muscovite & - & - & - & $\mathrm{A}$ & $\mathrm{A}$ & $\mathrm{A}$ \\
\hline & (Ca, Fe, Mg) oxides & - & - & $\mathrm{A}$ & $\mathrm{A}$ & $\mathrm{A}$ & $\mathrm{A}$ \\
\hline & Hematite & - & - & - & - & $\mathrm{A}$ & $\mathrm{A}$ \\
\hline
\end{tabular}

D: Dominant. Used for the component apparently most abundant, regardless of its probable percentage level.

SD: Sub-dominant. The next most abundant component(s) providing its percentage level is judged above about 20 .

A: Accessory. Components judged to be present between the levels of roughly 5 and $20 \%$.

Tr: Trace. Components judged to be below about $5 \%$. 
(a) $\mathbf{M 1 - 6 0 0}{ }^{\circ} \mathrm{C}:$ Transmitted light

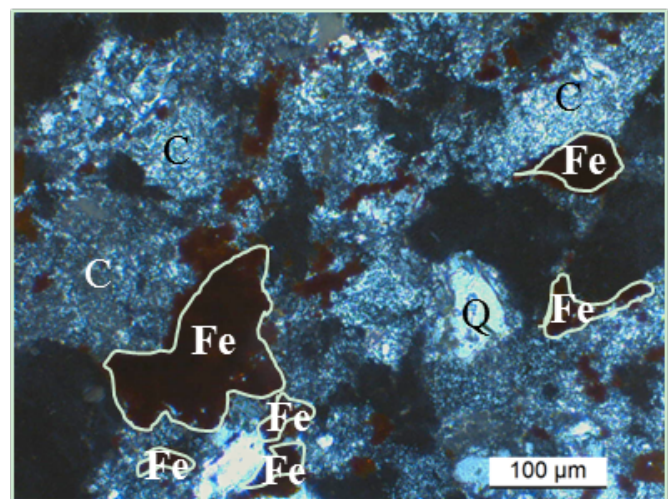

(c) $\mathrm{M} 1-900^{\circ} \mathrm{C}$ : Transmitted light

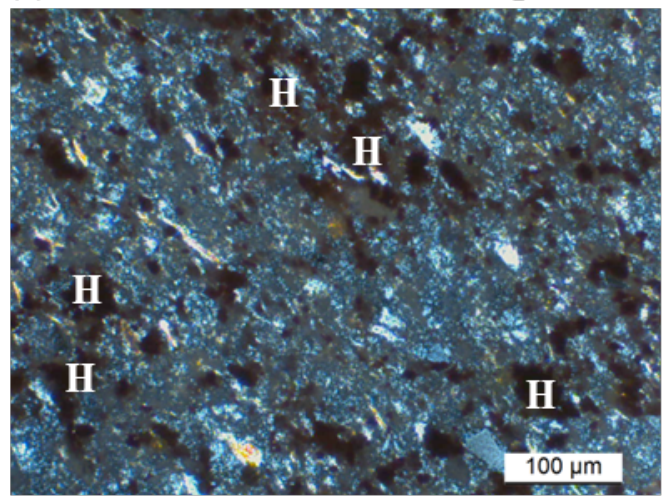

(b) $\mathrm{M} 1-600^{\circ} \mathrm{C}:$ Reflected light

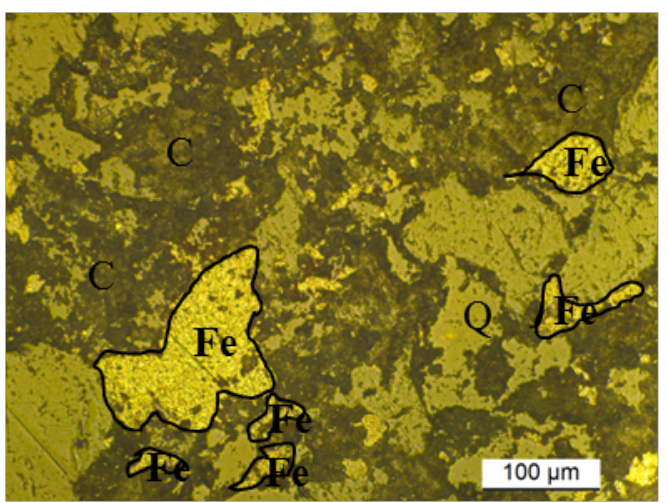

(d) $\mathrm{M1}-900^{\circ} \mathrm{C}:$ Reflected light

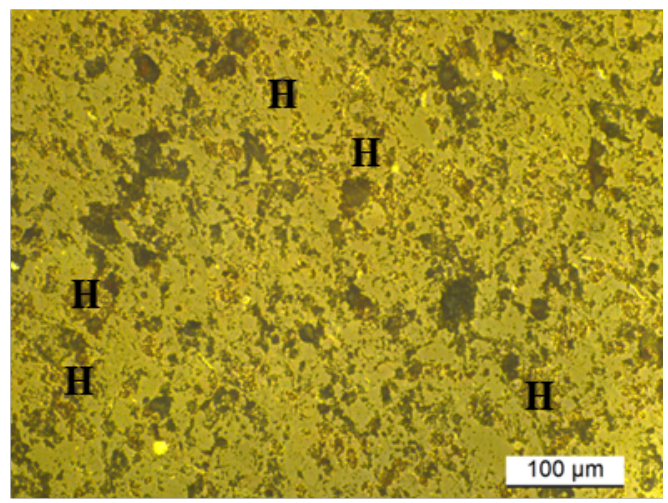

Q-Quartz C-Clay minerals Fe-Fe-bearing oxides H-Hermetite

Fig.9. Transmitted (a, c) and reflected (b, d) light microscopy analysis on thin sections of mudstone (M1) subjected to heating at temperatures of $600{ }^{\circ} \mathrm{C}(\mathrm{a}, \mathrm{b})$ and $900{ }^{\circ} \mathrm{C}(\mathrm{c}, \mathrm{d})$. 
(a) $\mathrm{M} 2-600{ }^{\circ} \mathrm{C}:$ Transmitted light

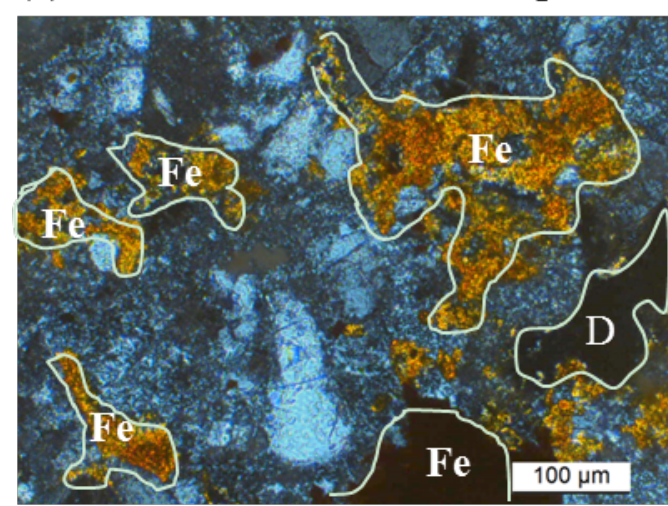

(c) ) $\mathbf{M 2 - 9 0 0}{ }^{\circ} \mathrm{C}:$ Transmitted light

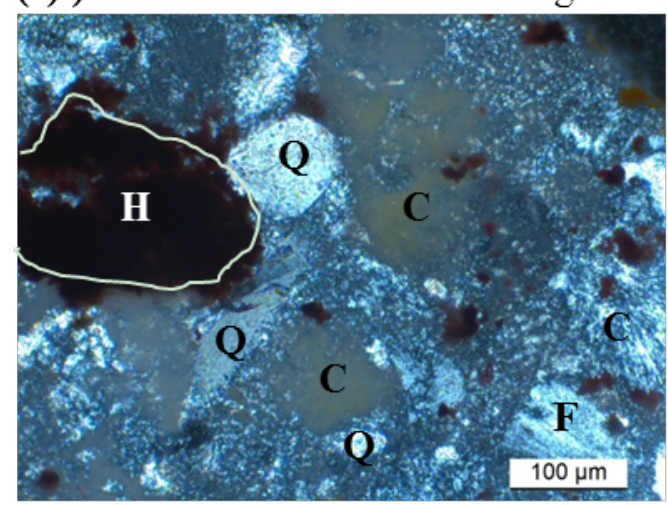

(b) ) $\mathrm{M} 2-600{ }^{\circ} \mathrm{C}:$ Reflected light

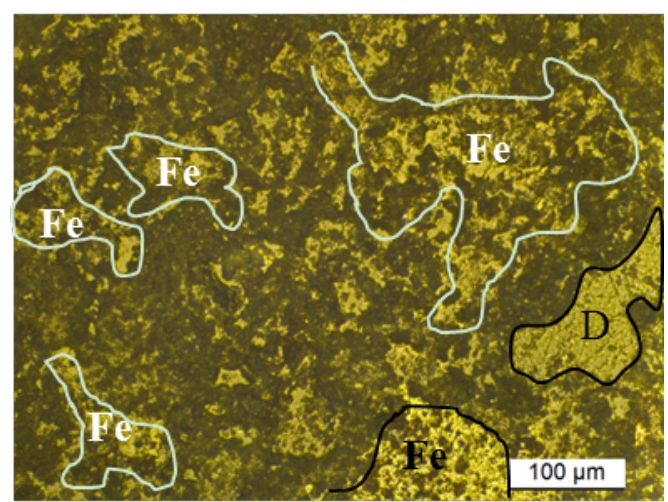

(d) ) $\mathrm{M} 2-900{ }^{\circ} \mathrm{C}:$ Reflected light

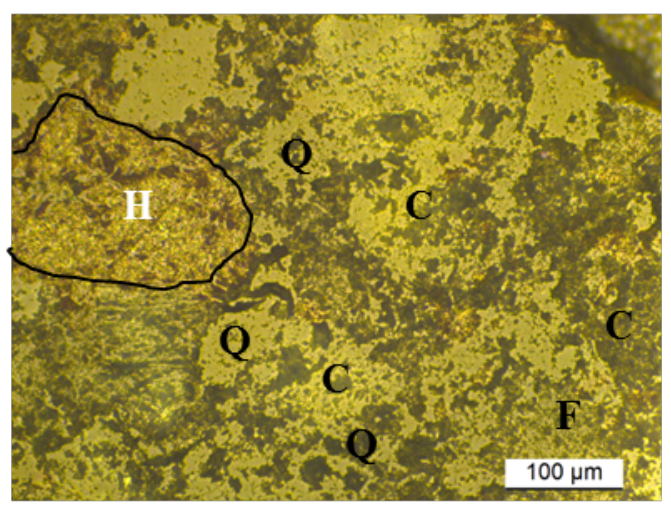

Q-Quartz F-feldspar C-Clay minerals D-dolomite Fe-Fe-bearing oxides H-Hermetite

Fig.10. Transmitted (a, c) and reflected (b, d) light microscopy analysis on thin sections of mudstone (M2) subjected to heating at temperature of $600{ }^{\circ} \mathrm{C}(\mathrm{a}, \mathrm{b})$ and $900{ }^{\circ} \mathrm{C}(\mathrm{c}, \mathrm{d})$.

\subsubsection{Changes in microstructure inferred by MIP and SEM}

Figure 11 presents the MIP results obtained on M1 (a, c) and M2 (b, d) heated at different temperatures after being subjected to splitting tests. For the M1, the total void ratio intruded by mercury $\left(\mathrm{e}_{\mathrm{MIP}}\right)$ tends to progressively increase with heating temperature. Overall, $\mathrm{e}_{\mathrm{MIP}}$ doubles (from 0.1 to 0.18 ) from 100 to $900^{\circ} \mathrm{C}$ (Fig.11a). This is accompanied by a progressive increase in pore volume density for a class pore size below $1.0 \mu \mathrm{m}$ without affecting much the dominant pore size when the heating temperatures are below $750{ }^{\circ} \mathrm{C}$ (Fig. 11c). An increase in temperature up to $900^{\circ} \mathrm{C}$ results in a significant increase in both dominant pore size and its corresponding density. In contrast, the overall PSD evolution of 
the M2 with temperature appears to take place gradually (Fig.11b, d). In other words, both the dominant pore size and its corresponding density progressively increases when the heating temperature is raised up to $750{ }^{\circ} \mathrm{C}$, beyond which a drastic change can be observed at $900^{\circ} \mathrm{C}$. These changes observed in Fig. 11 can be explained by the generation of microcracks either by differential thermal expansion of the different minerals or thermal reactions of the dominant minerals as discussed in the aforementioned section.

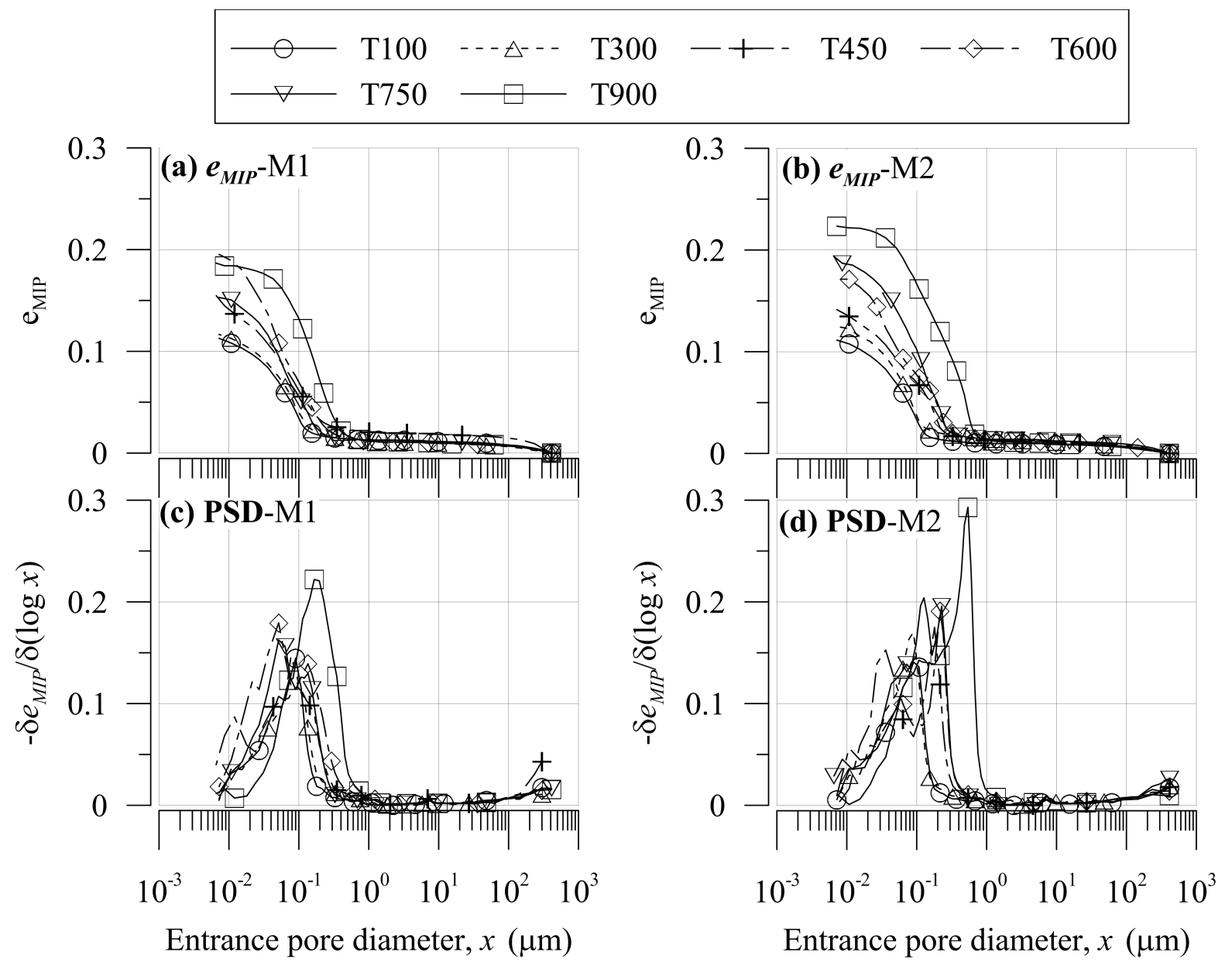

Fig.11. MIP results of heated M1 $(a, c)$ and M2 (b, d) in terms of total mercury intrusion void ratio $(a, b)$ and pore size distribution $(c, d)$

The occurrence of micro-cracks can be further confirmed by comparing back-scattering SEM images obtained from the polished thin sections of the rocks heated at $100{ }^{\circ} \mathrm{C}, 600{ }^{\circ} \mathrm{C}$ and $900{ }^{\circ} \mathrm{C}$, which also includes the dominate mineral determined based on the XRD data (Fig. 8 
and Table 3) and the chemical analysis results obtained by using EDS (Fig. 12). Both mudstones tested initially have a dense micro fabric (Fig 12a and 12b) and the boundaries between the different minerals are quite clear. These boundaries tend to be less clear when the specimens are subjected to heating treatment at $600{ }^{\circ} \mathrm{C}$ and $900{ }^{\circ} \mathrm{C}$. The formed cementation minerals such as Fe-bearing oxides in contact with Quartz and clay minerals can be clearly visualized (Fig.12c and 12d). Finally, micro cracks are clearly visible after heating the mudstones to $900^{\circ} \mathrm{C}$ (Fig. 12e and 12f). In particular, some micro cracks can be noticed within the sintered clay mineral of the mudstone (Fig. 12f). These observations are consistent with the PSD changes from MIP. 

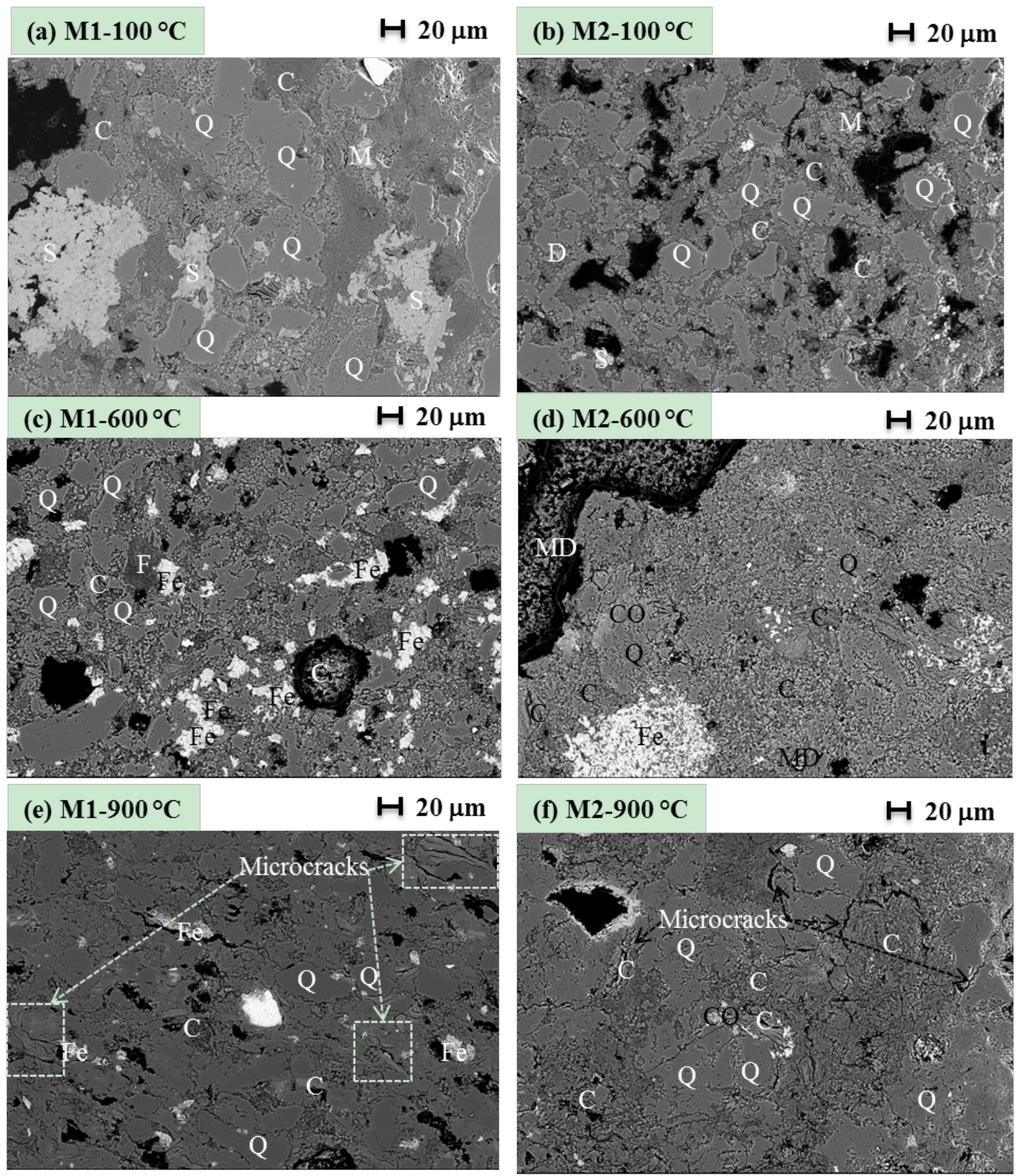

Q- Quartz, C- Clay minerals, M- Muscovite, F- Feldspar, S- Siderite (Ca, Mg, syn) D- Dolomite, Fe- Fe-bearing oxides ( $\mathrm{Ca}$ and $\mathrm{Mg}$ ), $\mathrm{CO}-(\mathrm{Ca}, \mathrm{Mg}, \mathrm{Fe})$ oxides MD-dehydraxylated muscovite

Fig.12. Back-scattering SEM images obatined from the thin sections of M1 (a, c,e) and M2 (b,d,f) subjected to heating at $100{ }^{\circ} \mathrm{C}(\mathrm{a}, \mathrm{b}), 600{ }^{\circ} \mathrm{C}(\mathrm{c}, \mathrm{d})$ and $900{ }^{\circ} \mathrm{C}(\mathrm{e}, \mathrm{f})$. 


\subsection{Discussion on multi-scale coupling}

The macroscopic response in terms of splitting tensile strength and small-strain shear stiffness of heated mudstones is expected to be inherently correlated to the microscopic changes in their minerology and microstructure. We can observe that the heating treatment has a strengthening effect on both mudstones tested when subjected to temperatures below $450{ }^{\circ} \mathrm{C}$ (Fig.5 and 6). Further increase in heating temperatures up to $900{ }^{\circ} \mathrm{C}$ leads to a significant degradation of splitting tensile strength and shear stiffness (Fig.5 and 6). The strengthening effect is likely attributed to the newly formed cementation minerals such as Febearing oxides (Fig. 8 and Table 3), which is a product of the decomposition of siderite $(\mathrm{Mg}$ and $\mathrm{Ca}$ ) presenting initially in both mudstones. The further increase in heating temperature results in microcracks generation as evidenced by both PSD from MIP (Fig.11) and SEM images (Fig.12), leading to the degradation of rock strength. In consequence, this degradation effect predominates over the strengthening effect related to the cementation development, which in turn results in the overall degradation of splitting tensile strength of both mudstone as well as their shear stiffness. In addition, starting with similar splitting tensile strength of intact mudstones heated at $100{ }^{\circ} \mathrm{C}$, the initial strengthening effect is more pronounced in case of M2. This may be due to the presence of high contents of both siderite and Fe-bearing dolomite in $\mathrm{M} 2$, producing more cementation agents when the specimens are subjected to heating treatment.

\section{Conclusions}

This study investigates the thermal effects on tensile strength of two Australian mudstone retrieved from a Hunter Valley mining site close to an existing underground coal seam fire (so-called Burning Mountain). First, the low-strain shear stiffness and splitting tensile 
strength were inferred via shear wave velocity measurements and splitting tests, respectively. The macro testing was followed by a comprehensive analysis at micro scale, which includes thermo gravimetric analysis (TGA), X-Ray diffraction (XRD), optical microscopy, backscattering scanning electron microscopy (SEM) and mercury intrusion porosimetry (MIP). These analyses provide a complete picture regarding the changes in the minerology and microstructure of the mudstones tested in response to the heating treatment. The discussion was made by linking the changes at both micro and macro scales. The main outcomes of this study can be summarized for three ranges of heating temperature as follows:

(1) At heating temperatures increasing from $100{ }^{\circ} \mathrm{C}$ to $450{ }^{\circ} \mathrm{C}$, the dehydration of adsorbed water in dominant minerals takes place for both mudstones tested, which is accompanied by the generation of some microcracks due to the differential thermal expansion of their dominant minerals. As the heating temperature increases, the dehydration effect results in the progressive mass loss of both mudstones, while the microcrack generation leads to a shift of the dominant pore size and an increase in void ratio. The changes in pore size distribution are much less pronounced for the mudstone due to its high content of clay minerals having relatively low thermal expansion potential. As a consequence, the unconfined compressive strength (UCS) of sandstone decreases. In contrast, the mudstone sees its UCS consistently increasing as temperature augments.

(2) At heating temperatures varying from $450{ }^{\circ} \mathrm{C}$ up to $900{ }^{\circ} \mathrm{C}$, the dehydroxylation of some dominant minerals occurs. This is the case of kaolinite and muscovite for the sandstone and illite/montmorillonite and muscovite for the mudstone. These reactions are accompanied by a decomposition of carbonates such as siderite (magnesian and calcian) and an increase in total void ratio. Below $750{ }^{\circ} \mathrm{C}$, the evolution of the pore size distribution of sandstone and mudstone differ. While a gradual shift of dominant pore size appears for the sandstone, no 
remarkable shift is visible for the mudstone. However, both rock types see their dominant pore size increase significantly at $900{ }^{\circ} \mathrm{C}$. Such increase directly translates into an increase of intrinsic permeability. Finally, in this temperature range, the variation in UCS of the rocks can be explained by two dominant mechanisms: (1) the thermal reactions of clay minerals and muscovite, (2) the generation of new bonding agents such as Fe-bearing oxides at $600{ }^{\circ} \mathrm{C}$ and hematite at $900{ }^{\circ} \mathrm{C}$.

\section{Acknowledgements}

The authors kindly acknowledge the financial support of the Australian Research Council (Linkage project ID: LP100200717) and the ARC Centre of Excellence for Geotechnical Science and Engineering. The authors would also like to express their gratitude to Prof. Terry Wall for allowing us to perform the heating treatment of rocks using their temperaturecontrolled furnace, to Dr. Yanyan Sun for her help with the preparation of thin sections and optical microscopy observation, and to Dr. David Phelan and Dr. Jenny Zobec for their help with scanning electron microscopy observation and X-ray diffraction analysis, respectively.

\section{References}

ASTM-D4404-10 (2010) Standard Test Method for Determination of Pore Volume and Pore Volume Distribution of Soil and Rock by Mercury Intrusion Porosimetry. ASTM Int West Conshohocken, PA pp.1-7. doi: 10.1520/D4404-10.

ASTM-D4543-08 (2008) Standard Practices for Preparing Rock Core as Cylindrical Test Specimens and verifying Conformance to Dimensional and Shape Tolerances. ASTM Int West Conshohocken, PA pp.1-9. doi: 10.1520/D4543-08.

ASTM-D7012-14 (2014) Standard Test Method for Compressive Strength and Elastic Moduli of Intact Rock Core Specimens under Varying States of Stress and Temperatures. ASTM Int West Conshohocken, PA pp.1-9. doi: 10.1520/D7012-10.1

Beamish BB, Barakat M a., St. George JD (2001) Spontaneous-combustion propensity of New Zealand coals underadiabatic conditions. Int J Coal Geol 45:217-224. doi: 10.1016/S0166-5162(00)00034-3 
Bell FG, Bullock SET, Hälbich TFJ, Lindsay P (2001) Environmental impacts associated with an abandoned mine in the Witbank Coalfield, South Africa. Int J Coal Geol 45:195-216. doi: http://dx.doi.org/10.1016/S0166-5162(00)00033-1

Berkman DA (2001) Field geologist's manual, 4th ed. Carlton, Vic. : Australasian Institute of Mining and Metallurgy

Brotóns V, Tomás R, Ivorra S, Alarcón JC (2013) Temperature influence on the physical and mechanical properties of a porous rock: San Julian's calcarenite. Eng. Geol. 167:117127.

Buzzi O, Sieffert Y, Mendes J, et al (2013) Strength of an Australian Coal Under Low Confinement. Rock Mech Rock Eng. doi: 10.1007/s00603-013-0493-5

David C, Menéndez B, Darot M (1999) Influence of stress-induced and thermal cracking on physical properties and microstructure of La Peyratte granite. Internatioanl J Rock Mech Min Sci 36:433-448.

Deer WA, Howie RA, Zussman J (2013) An Introduction to the Rock-forming Minerals, 3rd ed. London: Mineralogical Society

Dmitriev A (1972) Physical properties of rocks at high temperatures. Folia Microbiol (Praha) 17:117-125. doi: 10.1007/BF02877909

EL-Dieb AS, Hooton RD (1994) Evaluation of the Katz-Thompson model for estimating the water permeability of cement-based materials from mercury intrusion review of KatzThompson theory. Cem Concr Res 24:443-455.

Hajpál M, Török A (2004) Mineralogical and colour changes of quartz sandstones by heat. Environ Geol 311-322. doi: 10.1007/s00254-004-1034-z

Hajpál M, Török Á (1998) Petrophysical and mineralogical studies of burnt sandstones. Proc 2 nd Int PhD Symp 1-9.

Ide TS, Pollard D, Orr FM (2010) Fissure formation and subsurface subsidence in a coalbed fire. Int J Rock Mech Min Sci 47:81-93. doi: 10.1016/j.ijrmms.2009.05.007

Katz a. J, Thompson a. H (1986) Quantitative prediction of permeability in porous rock. Phys Rev B 34:8179-8181. doi: 10.1103/PhysRevB.34.8179

Katz a. J, Thompson a. H (1987) Prediction of rock electrical conductivity from mercury injection measurements. J Geophys Res 92:599. doi: 10.1029/JB092iB01p00599

Kaymakci E, Didari V (2002) Relations between coal properties and spontaneous combustion parameters. Turkish J Eng ... 26:59-64. doi: 10.1016/S0140-6701(03)90480-2

Keshavarz M, Pellet F, Loret B (2010) Damage and changes in mechanical properties of a gabbro thermally loaded up to 1,000 C. Pure Appl Geophys 167:1511-1523. doi: 10.1007/s00024-010-0130-0 
Kuenzer C, Zhang J, Tetzlaff A, et al (2007) Uncontrolled coal fires and their environmental impacts : Investigating two arid mining regions in. Appl Geogr 27:42-62. doi:

10.1016/j.apgeog.2006.09.007

Liu XF, Collin F, Buzzi O, Sloan SW (2012) Numerical modelling of ground temperature evolution as a result of underground coal fire. Aust Geomech J 47:27-32.

Luo, J. and Wang L (2011) High-Temperature Mechanical Properties of Mudstone in the Process of Underground Coal Gasification. Rock Mech Rock Eng. doi: 10.1007/s00603011-0168-z

Moore MD, Reynolds RC (1989) X-ray Diffraction and the Identification and Analysis of Clay Minerals. Oxford University press, Oxford, England

Pansu M, Gautheyrou J (2006) Handbook of Soil Analysis- Mineralogical, Organic and inorganic methods. Springer Berlin Heidelberg, The Netherlands

Ranjith PG, Viete DR, Chen BJ, Perera MS a. (2012) Transformation plasticity and the effect of temperature on the mechanical behaviour of Hawkesbury sandstone at atmospheric pressure. Eng Geol 151:120-127. doi: 10.1016/j.enggeo.2012.09.007

Rattigan JH (1967) Phenomena about Burning Mountain, Wingen, New South Wales. Aust J Sci 30:183-184.

Sinha A, Singh VK (2005) Spontaneous Coal Seam Fires: A Global Phenomenon. ERSEC Ecological Book Series - 4 on Coal Fire Research. Beijing, PR China, pp 42-66

Somerton W (1992) Thermal properties and temperature-related behavior of rock/fluid systems.

Stracher GB, Taylor TP (2004) Coal fires burning out of control around the world: thermodynamic recipe for environmental catastrophe. Combustion 59:7 - 17. doi: 10.1016/j.coal.2003.03.002

Tian H, Kempka T, Xu N, Ziegler M (2012) Physical properties of sandstones after high temperature treatment. Rock Mech rock ... 1113-1117. doi: 10.1007/s00603-012-0228$\mathrm{z}$

Tian H, Ziegler M, Kempka T (2014) Physical and mechanical behavior of claystone exposed to temperatures up to $1000^{\circ} \mathrm{C}$. Int J Rock Mech Min Sci 70:144-153. doi: 10.1016/j.ijrmms.2014.04.014

Voigt S, Rüter H (2005) Spontaneous Coal Seam Fires: The Sino-German Coal Fire Research Initiative. ERSEC Ecological Book Series - 4 on Coal Fire Research. Beijing, PR China, pp 82-91

Washburn EW (1921) The dynamics of capillary flow. Phys Rev 17:273-283. doi: 10.1103/PhysRev.17.273 
Wolf K-HAA (2006) The interaction between underground coal fires and their roof rocks. TU Delft, Delft University of Technology

Yavuz H, Demirdag S, Caran S (2010) Thermal effect on the physical properties of carbonate rocks. Int J Rock Mech Min Sci 47:94-103. doi: 10.1016/j.ijrmms.2009.09.014

Zhang L, Mao X, Lu A (2009) Experimental study on the mechanical properties of rocks at high temperature. Sci China Ser E Technol Sci 52:641-646. doi: 10.1007/s11431-0090063-y

ASTM D3967 - 08 Standard Test Method for Splitting Tensile Strength of Intact Rock Core Specimens 
List of Tables and figures: 